\title{
PRODUCTION LOGISTICS SIMULATION AND OPTIMIZATION OF INDUSTRIAL ENTERPRISE BASED ON FLEXSIM
}

\author{
Wang, Y. R. \& Chen, A. N.* \\ School of Management \& Economics, North China University of Water Resources and Electric Power, \\ Zhengzhou City, Henan Province, P. R. China \\ E-Mail: can5151@126.com (* Corresponding author)
}

\begin{abstract}
This paper proposes the research method to comprehensively apply the time Petri net model and the Flexsim simulation model by taking interior assembling and production logistics system of an automobile manufacturing assembly workshop as the application background, and taking improvement for the production efficiency and production value of the logistics system as the target. Using this method, we can simulate the actual production logistics, analyse the results and identify bottleneck problems, and propose targeted optimization methods to improve processes, reduce waste, improve efficiency, and prove the rationality and validity of the research method.

(Received, processed and accepted by the Chinese Representative Office.)
\end{abstract}

Key Words: Production Logistics System, Simulation, Petri Net, Flexsim, Optimization

\section{INTRODUCTION}

With the rapid development of the global economy, manufacturing technology has become increasingly skilled. The competition model of traditional manufacturing industry has focused on size and quality, while the modern manufacturing industry pays more attention to speed and efficiency [1]. In view of current automobile manufacturing enterprises in China, it is common that the dynamics of the whole manufacturing system and adaptability of the environment are insufficient. Furthermore, cross-flow operation, repeating operation, material backflow, process waiting and other conditions have become serious [2, 3]. With the development of computers, the modelling and simulation technology are used in production logistics, to provide good support for optimization of the enterprise layout and the production logistics system, so as to advance, prevent or ameliorate various problems in the actual operation. According to existing research [4-6], the Petri net model and Flexsim simulation software are applied to the study of discrete dynamic systems, and it is an effective method for modelling and simulation of production logistics at present [7, 8].

In this paper, Petri net modelling tool and Flexsim simulation software are used, combining the production background of an automobile production, the interior line section of a company's general assembly workshop is used as the exploring object. The reason for low production efficiency of the original production line is identified through analogue simulation, and optimization is carried out. A reasonable production logistics process is given, achieving a scientific allocation of resources, and improving production efficiency, so as to enhance the energy-producing effects of the whole assembly workshop. This method can be applied to similar flexible manufacturing enterprises, to provide decision support for optimization, management and control of similar production logistics system.

\section{PRODUCTION PROCESS AND LOGISTICS CHARACTERISTICS FOR GENERAL AUTOMOBILE ASSEMBLE FACTORY STAGE I}

The process level of a general assembly workshop determines the overall vehicle quality. At the same time, it is very complex, with a large quantity of stations. On the premise of having 
no effect on research results, the process will be simplified. The total technological process of the general assembly workshop is shown in Fig. 1.

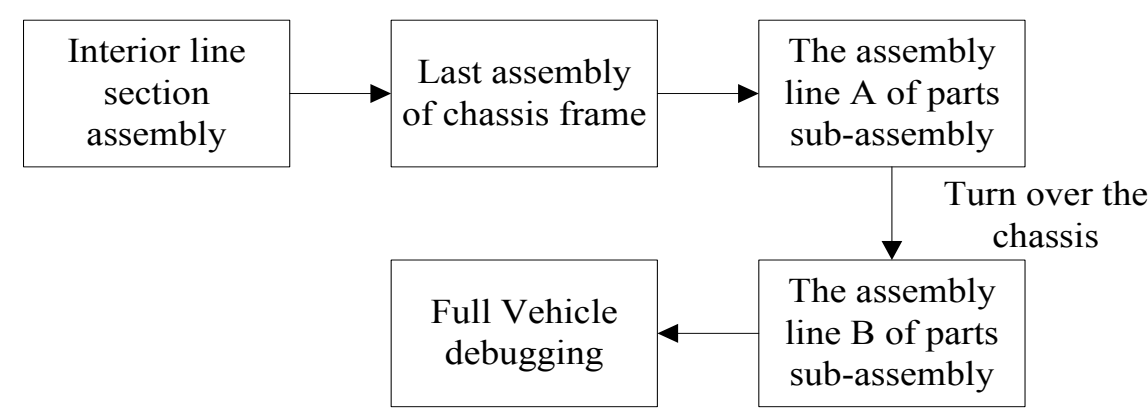

Figure 1: Production technology process of assembly workshop.

The technological process of the interior line assembly is shown in Fig. 2.

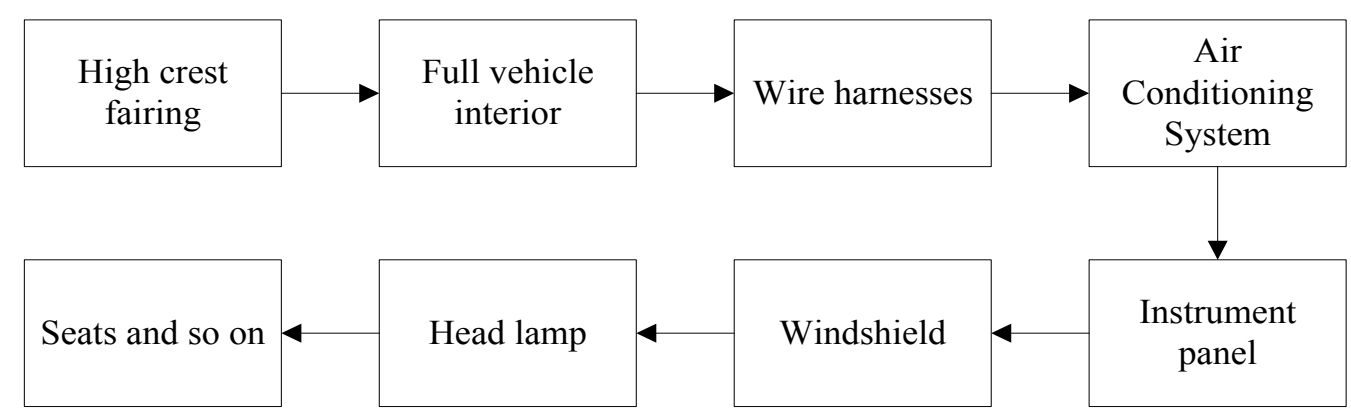

Figure 2: Production technology process of interior line section assembly.

After the completion of general assembly Line B, it will enter into the process of inspecting the whole vehicle. The engine will be started, and the whole vehicle will run. Then it will enter into the next section for future testing and coordination. Then it will be driven off the general assembly workshop; namely, the whole assembly process is completed and it will go off the assembly line. Finally, it will enter into the road testing stage, and the quality management department will carry out related inspections of the vehicle's quality, environmental protection and other comprehensive performance.

According to the actual research and production process, in the general assembly workshop, there are a larger number of complicated processes in interior assembly line section. If it is not handled properly, there will be an imbalance in the production line, resulting in parts of stations to be idle. Meanwhile, the processing speed for other parts of the stations is slow, so they cannot be synchronized to the tact time of the entire system. Therefore, the interior line section of the above described general assembly workshop is chosen for process optimization of production logistics, and to improve the operational efficiency.

\section{PETRI NET MODELLING FOR INTERIOR LINE PRODUCTION LOGISTICS}

\subsection{Modelling principles of Petri}

The system of assembly production logistics simulation of automobiles can realize a multipath logistics balance, capacity balance, ability balance and time balance $[9,10]$ under a special evaluation index, such as minimum waiting time, minimum total process time or set tact time. In automobile assembly, several processes form one station and several stations 
form an assembly line [11]. Each station must finish all its processes, and then the product can be moved on to the corresponding next station. All the steps are gradually completed according to the production plan and technical process. According to this, the model will be very huge, which is difficult to be used in problems analysis and settlement, and may even cannot be solved.

So, this paper chooses the station as the basic modelling object. Furthermore, the assembly order of each station in the production process will be set and limited. The modelling method is equal to the establishment of the whole process from the starting process to the last process.



Figure 3: Timed Petri net for production logistics of truck interior assembly line section.

Table I: The meaning of place and changes in timed Petri net.

\begin{tabular}{|c|l|c|l|}
\hline Place & \multicolumn{1}{|c|}{ Meaning } & Changes & \multicolumn{1}{|c|}{ Meaning } \\
\hline P0 & Turn to the interior line section & $\mathrm{t} 1$ & High crest fairing assembly \\
\hline P1 & High crest fairing assembly completed & $\mathrm{t} 2$ & Full vehicle interior assembly \\
\hline P2 & Full vehicle interior assembly completed & $\mathrm{t} 3$ & Wire harnesses assembly \\
\hline P3 & Wire harnesses assembly completed & $\mathrm{t} 4$ & Air conditioning system assembly \\
\hline P4 & Air conditioning system assembly completed & $\mathrm{t} 5$ & Instrument panel assembly \\
\hline P5 & Instrument panel assembly completed & $\mathrm{t} 6$ & Windshield assembly \\
\hline P6 & Windshield assembly completed & $\mathrm{t} 7$ & Headlamp assembly \\
\hline P7 & Headlamp assembly completed & $\mathrm{t} 8$ & Seats and other accessories assembly \\
\hline P8 & Seats and other accessories assembly & & \\
\hline
\end{tabular}

\section{FLEXSIM MODEL FOR INTERIOR LINE PRODUCTION LOGISTICS OF THE GENERAL ASSEMBLY WORKSHOP}

\subsection{Flexsim simulation modelling principles}

Flexsim simulation software can highlight the 3D display effect for the simulation objects, and make modelling and debugging easy and convenient. Furthermore, the model scalability is strong, which is easy to use cooperatively with other software [12, 13]. The basic steps of simulation can be divided into six steps: building the model layout, defining the logistics processes, setting the parameters, compiling and running the model, outputting the simulation results and analysis of simulation results [14].

This paper takes the assembly section in the interior line of an automobile manufacturing company as the simulation objects, which includes eight stations. Based on actual production, this author makes parameter settings, analogue simulation on workshop assembly conditions of three main vehicle orders, A, B, and C. Research is carried out on tact time as the evaluation index, counting production efficiency, vacancy rate and degree of obstruction of each station. Understanding whether the logistics process arrangement is reasonable and 
whether the scheduling policies are appropriate through simulation results, adjustments are made for the problems so as to improve overall cooperation and coordination of each process in the assembly and production logistics of interior line. This will achieve structural optimization and function optimization of the system processes.

Analogue simulation focuses on solving the problems of bottlenecks in targeted production logistics. So it is necessary to simplify and make reasonable assumptions for the production logistics system [15]. Impacts of non-related factors are excluded, and it mainly includes six factors [16]:

(1) For three types of trucks, in order to fulfil the production order, one order can only correspond to one type of truck;

(2) During production, order quantity of all assembly lines is sufficient, and there is no idle accessibly line;

(3) There is no unexpected fault during the whole logistics operation period, and there is enough manpower and material resources to meet the operational needs of the entire system;

(4) This author ensures that every procedure has a sufficient supply of raw materials, to avoid stagnation of the assembly line due to insufficient supply of raw materials;

(5) Operating of processors in the model will correspond to operating by staff at each station;

(6) The entire assembly time also includes time consumption for preparation work, and each station can be put into operation at any time.

\subsection{Collation of related data}

Collection and collation of related data involved in the simulation process main include the following points:

(1) Assembly tact: Production tact for the interior line of stage I in the general assembly workshop of the enterprise is $3.5 \mathrm{~min}$, and all stations can be synchronized;

(2) Production time and order quantity: We will collate the quantity of truck orders and truck quantity (A, B and C types) of the enterprise from April to June 2014, of which the total quantity of truck orders for the three types of trucks are 49, 50 and 50. So we can regard the order quantity as an even distribution. We will carry out statistical analysis for the quantity of ordered trucks by origin software, as shown in Fig. 4, which shows that the quantity of trucks meets normal distribution $\mathrm{N}(25,5)$.

(3) Operating time of station: In order to regulate the operation and ensure a smooth logistics system, the general assembly workshop makes clear regulation of operating time of each station. Each worker must strictly follow this regulation, and the error level will be controlled within half a minute in the actual operation. The standard operating time of each station is shown in Table II. For example, the standard operating time of a high top guide hood is $2.3 \mathrm{~min}$. So according to the error control, the setting time for running the processor will be $1.8 \mathrm{~min}-2.8 \mathrm{~min}$. Other stations can be calculated with the same method.

\subsection{Establishment of Flexsim simulation model}

The models are established according to the production technical process of the general assembly workshop (Fig. 1), assembly process of the interior line (Fig. 2) and the Petri net model diagram of the interior assembly line section (Fig. 3). The assembly model layout for the interior line of the general assembly workshop is shown in Fig. 5. The requirements of the model are shown in Table III. 


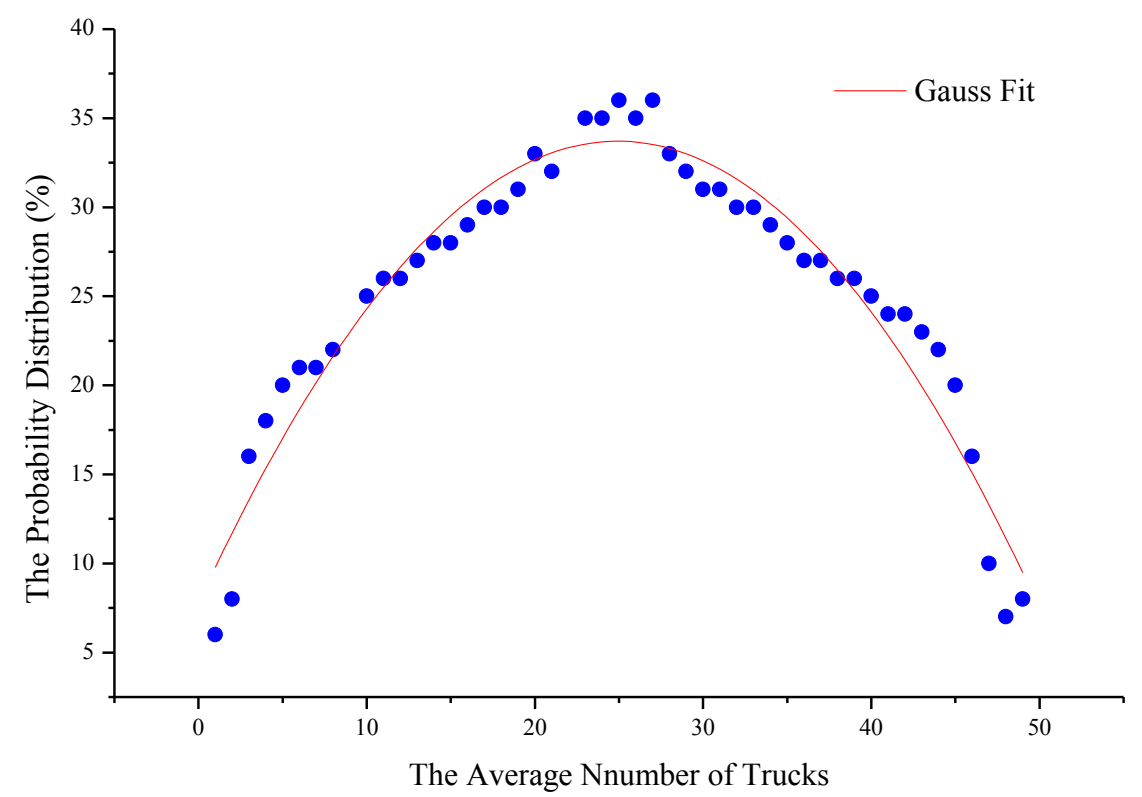

Figure 4: Fitting curve of truck quantity.

Setting of main parameters:

- The setting of the source parameter will be reached according to the time interval, which is $3.5 \mathrm{~min}$;

- The setting of the separator parameter will be used to distinguish the three types of trucks. There is no assembly line actually, and the set process time is 0 ;

- The setting of processor parameter will be set according to the production time of different processes. The code completion time will be set according to data in Table II;

- The length setting of the conveyor parameter is $3 \mathrm{~m}$; the speed of the conveyor is 0.85 $\mathrm{m} / \mathrm{min}$; the transit time is $3.5 \mathrm{~min}$; and the set maximum capacity is 1 .

Table II: The standard work time of each station.

\begin{tabular}{|l|c|c|c|}
\hline \multirow{2}{*}{\multicolumn{1}{|c|}{ Station }} & \multicolumn{3}{|c|}{ Standard work time (Unit: minute) } \\
\cline { 2 - 4 } & A Truck & B Truck & C Truck \\
\hline High crest fairing assembly & 2.3 & 2.2 & 2.1 \\
\hline Full vehicle interior assembly & 2.8 & 2.8 & 2.0 \\
\hline Wire harnesses assembly & 2.9 & 2.7 & 2.3 \\
\hline Air conditioning system assembly & 2.3 & 2.6 & 2.0 \\
\hline Instrument panel assembly & 2.1 & 2.3 & 2.1 \\
\hline Windshield assembly & 2.2 & 2.2 & 1.7 \\
\hline Head lamp assembly & 2.4 & 2.4 & 1.9 \\
\hline Seats assembly and so on & 3.0 & 3.0 & 2.3 \\
\hline
\end{tabular}

Table III: Requirements of the Flexsim model.

\begin{tabular}{|c|l|}
\hline Name of Flexsim Requirement & \multicolumn{1}{|c|}{ Description } \\
\hline Source & Produce order \\
\hline Queue & Buffer cache \\
\hline Separator & Resolve the order into a certain number of processing trucks \\
\hline Processor & Operating region \\
\hline Conveyor & Transfer between different stations \\
\hline Object & Processing trucks \\
\hline Sink & Process after the interior line section assembly is completed \\
\hline
\end{tabular}


The above set parameters can be completed by editing process codes. In actual production, part of the process will differ from the simulation system [17], such as the transmit time of the conveyor. But the focus of this article is to study the working efficiency of each station, and transit time of the conveyor belt does not affect the overall condition. So, the above settings can ensure consistency between the simulation model and actual logistics operation.



Figure 5: Model layout of interior line section assembly.

\subsection{Operations of Flexsim simulation model}

The above set model will be operated. Fig. 6 shows the operating status of the model. The operating result for the production tact of $3.5 \mathrm{~min}$ is collated in Table IV.

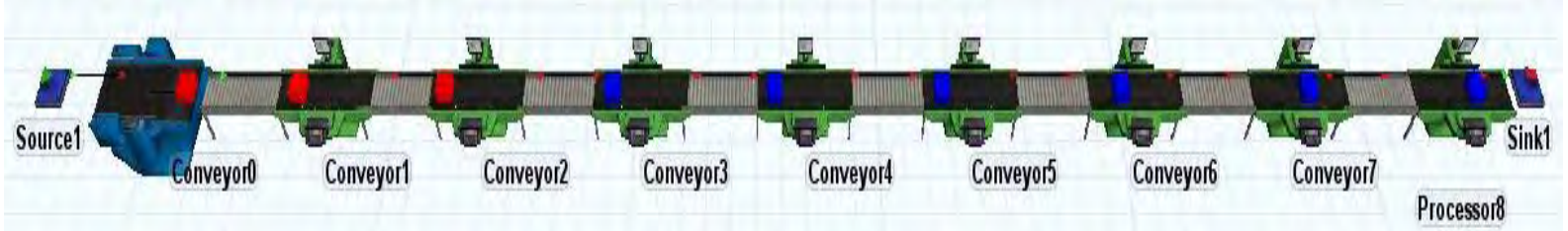

Figure 6: Running status at some time of the interior line section assembly simulation model.

Table IV: Simulation result when the tact time is 3.5 minute.

\begin{tabular}{|c|l|c|c|c|c|c|}
\hline \multicolumn{2}{|c|}{ Object } & Idle & Processing & Busy & Blocked & Empty \\
\hline Processor1 & High crest fairing assembly & $34.26 \%$ & $66.04 \%$ & $0.00 \%$ & $0.00 \%$ & $0.00 \%$ \\
\hline Processor2 & Full vehicle interior assembly & $20.54 \%$ & $75.85 \%$ & $0.00 \%$ & $3.04 \%$ & $0.00 \%$ \\
\hline Processor3 & Wire harnesses assembly & $26.98 \%$ & $68.59 \%$ & $0.00 \%$ & $2.66 \%$ & $0.00 \%$ \\
\hline Processor4 & Air conditioning system assembly & $21.09 \%$ & $78.10 \%$ & $0.00 \%$ & $0.00 \%$ & $0.00 \%$ \\
\hline Processor5 & Instrument panel assembly & $27.67 \%$ & $72.83 \%$ & $0.00 \%$ & $0.00 \%$ & $0.00 \%$ \\
\hline Processor6 & Windshield assembly & $39.66 \%$ & $62.27 \%$ & $0.00 \%$ & $0.00 \%$ & $0.00 \%$ \\
\hline Processor7 & Headlamp assembly & $32.47 \%$ & $68.76 \%$ & $0.00 \%$ & $0.00 \%$ & $0.00 \%$ \\
\hline Processor8 & Seats and other accessories assembly & $21.32 \%$ & $77.98 \%$ & $0.00 \%$ & $0.00 \%$ & $0.00 \%$ \\
\hline
\end{tabular}

According to the simulation result shown in Table IV, when the assembly tact is $3.5 \mathrm{~min}$, in addition to slight blockage in the whole vehicle interior assembly and wire assembly process, blockage of other processes are 0 , indicating that the technical process line cannot cause congestion or overload within the allowable range. Additionally, compared to idle and working conditions of the eight stations, the table shows that the assembly time of the eight stations are sufficient, and the least idleness accounts for $20.54 \%$. These results show that the interior assembly line production logistics system of the current general assembly workshop has a larger optimization space. We can carry out targeted optimization, determine improvements in appropriate ways, and thereby we can improve the productivity of a general assembly plant. 


\section{OPTIMIZATION OF PRODUCTION LOGISTICS SYSTEM}

\subsection{Optimization target}

According 7R principles of logistics [18], all enterprises will be well able to discover problems, and eliminate defects and waste in every detail, making the most scientific and rational logistics system, and improving efficiency and enhancing the value $[19,20]$. In this paper, we take the analogue simulation for the interior assembly line process of the general assembly workshop in order to determine the irregularities of the processes and make improvements and optimization, to achieve maximum value and efficiency, while providing reference and provide value for simulation and optimization of other processes. According to results of simulation statistical data in Section 3, the idle time of each station is the object to eliminate, and it is also the optimization object for the interior assembly line process.

If the assembly time of products at a work station is less than the tact time, it will result in idle time of that station until each station in the assembly line being moved again. The longer the idle time is, the lower the productivity of that station will be. We will control the tact time and improve the operating efficiency of each station. If the working time of products to be assembled at a work station is more than tact time, it will result in stagnation of the assembly line and an overload of the station and will halt production of other stations. So, we will try to avoid undesirable phenomena of overloaded station. Therefore, in order to improve production efficiency and value, we will maximize efficiency, improve the utilization of the station, and reduce the overload time (blocked) and idle time (idle). Usage of the objective function is shown in Eq. (1):

$$
F=\sum_{1}^{n} \text { idle }_{i}+\sum_{1}^{n} \text { blocked }_{i}
$$

where $i(i=1,2,3, \ldots, n)$ is the number of each station in the assembly line.

The formula will be applied to the interior assembly line of the general assembly workshop in the article. We will analyse different tact times and operating times of each station, and determine the optimization objective function with Eq. (2):

$$
F=\sum_{i=1}^{8} \text { idle }_{i}+\sum_{i=1}^{8} \text { blocked }_{i}+\sum_{j=0}^{7} \text { blocked }_{j}
$$

where, $i$ is the number of eight stations in the interior assembly line process, and $j$ is the number of eight conveyor belts in the interior assembly line process.

\subsection{Optimization method}

There are usually three methods to reduce overload time and idle time:

(1) Improving the production process or change the layout of the workshop [21]. This method can achieve good results, but due to the high cost and long period of response and effect chain issues, it is more frequently used in large projects with very severe bottleneck problems;

(2) Increase or replace equipment and increase training of workers when logistics node occurs in a problem [22];

(3) Setting reasonable assembly tact time, conduct several tests using analogue simulation, and analyse various test results, so as to obtain the optimal tact time. The third method taken in this paper carries out optimization for the objective function by setting a reasonable tact time. This method has low cost, a short cycle, is easy to implement, so it can be flexibly applied to optimize various production logistics systems. 


\subsection{Optimization of interior assembly line production logistics}

Table IV shows that the idleness rates of eight stations in the original line are all above $20 \%$, and there is almost no overloading. So, by shortening the original tact time, the optimal solution of the objective function (2) can be obtained. The new tact time is based on $3.5 \mathrm{~min}$, and then 0.25 minutes is subtracted in turn, and the parameter setting and analogue simulation calculation will be carried out by Flexsim. Results of simulation calculation corresponding to tact time will be collated, and values of the objective function (2) can be made, as shown in Fig. 7.

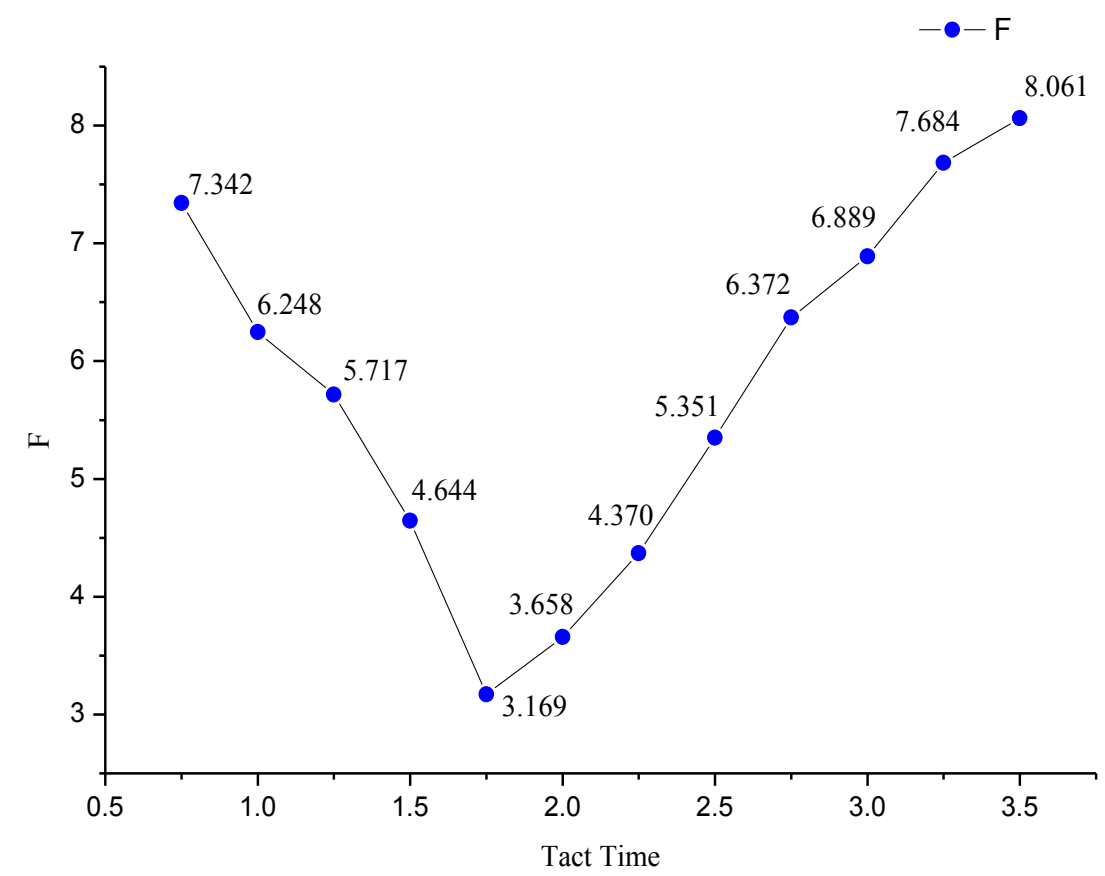

Figure 7: Curve relation between $F$ and tact time.

It is evident from Fig. 7, when the tact time is $1.75 \mathrm{~min}$, the $F$ value is at the minimum; namely, the idle time and overload time are minimums. Compared to the tact time of $3.5 \mathrm{~min}$, the $F$ value is decreased by $60.69 \%$. According to the rule shown in Fig. 7, when the tact time is less than 1.75 min, overloaded stations will increasingly appear, and when the tact time is greater than $3.5 \mathrm{~min}$, the tact time and idle time increases.

In order to get a clearer comparison of results before and after optimization, we will compare the station utilization and station vacancy rates when the tact time is at $3.5 \mathrm{~min}$ and 1.75 min, as shown in Figs. 8 and 9.

Figs. 8 and 9 show that when the tact time is set at $1.75 \mathrm{~min}$, the station utilization is significantly improved, while the vacancy rate is significantly reduced, indicating that assembly efficiency has improved significantly. Therefore, setting a reasonable tact time has a significant effect in improving the operating efficiency of the production logistics system.

\section{CONCLUSION}

In this paper, we combine the actual production logistics system of an automobile manufacturer, comprehensively use Petri net model and Flexsim simulation software for simulating, and propose an effective optimization method based on the simulation results. 


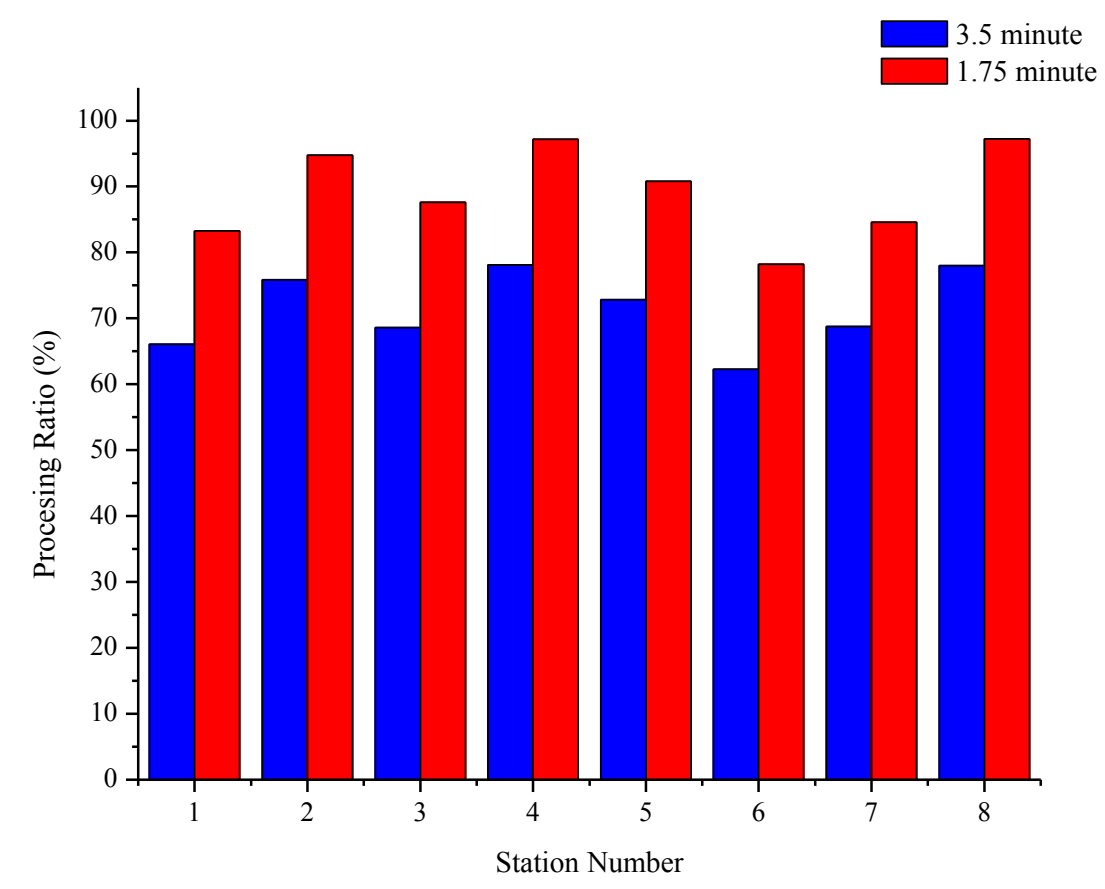

Figure 8: Comparison of processing ratio.

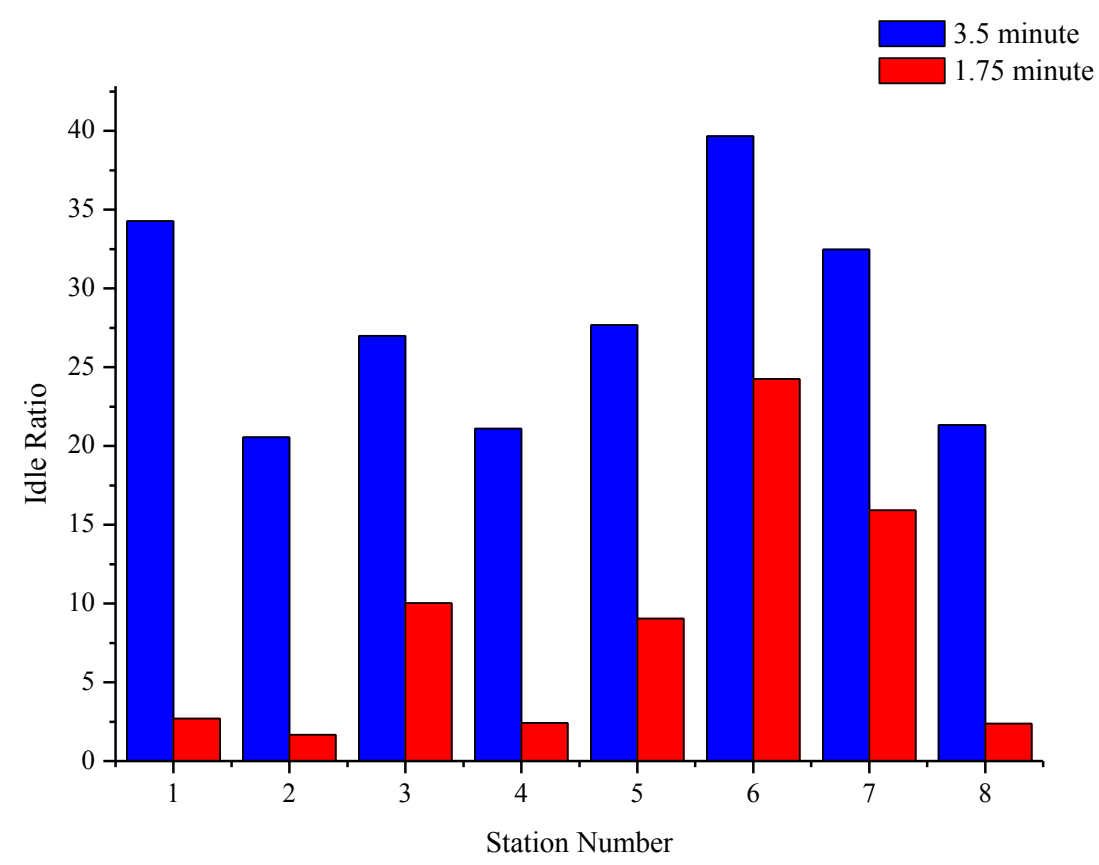

Figure 9: Comparison of idle ratio.

The main conclusions are as follows:

(1) We can comprehensively use the Petri net model and Flexsim simulation software to carry out simulation research on the production logistics system. It is convenient and flexible, with high visualization. We are able to accurately analyse the production logistics system, and make targeted improvements and optimizations to the logistics system;

(2) For the interior assembly line logistics systems in this paper, we carry out analogue simulation analysis through the Petri net model and Flexsim, propose reasonable optimization method, and improve the production efficiency of the logistics system through setting a rational tact time. 


\section{REFERENCES}

[1] Xu, H.; Mei, Q. (2007). Research on production logistics of manufacturing in China, Modern Logistics, Vol. 53, No. 2, 53-54

[2] Tang, L.-L. (2013). The problems of production logistics in manufacturing enterprises and the countermeasures, Journal of Huaihai Institute of Technology (Humanity and Social Sciences Edition), Vol. 11, No. 16, 28-30

[3] Xiang, H.; Li, M.; Wang, Z.-M. (2007). Empirical study on workshop logistics improvement, Value Engineering, Vol. 26, No. 6, 86-89

[4] Jung, C.; Kim, H.-J.; Lee, T.-E. (2015). A branch and bound algorithm for cyclic scheduling of timed Petri nets, IEEE Transactions on Automation Science and Engineering, Vol. 12, No. 1, 309-323, doi:10.1109/TASE.2013.2285221

[5] Qi, Y.-N.; Tang, M.-C.; Zhang, M. (2014). Mass customization in flat organization: The mediating role of supply chain planning and corporation coordination, Journal of Applied Research and Technology, Vol. 12, No. 2, 171-181, doi:10.1016/S1665-6423(14)72333-8

[6] Yang, Y.; Lu, C.-G.; Chen, J.-P.; Liu, L.-M. (2009). Modelling and simulation study of the production system based on Flexsim, Modern Manufacturing Engineering, Vol. 10, No. 12, 42 46

[7] Shi, Y.-Q.; Xiao, S.-M.; Ou, D.-Y. (2008). Analysis on production logistics system based on Flexsim simulation software, Manufacturing Technology \& Machine Tool, Vol. 30, No. 6, 137143

[8] Yang, S.-Q.; Zhang, H.-F., Li, D.-X. (2008). FMS logistics system modeling and simulating based on Petri nets, Computer Engineering and Applications, Vol. 44, No. 22, 226-228

[9] Zhang, G.-B.; Fu, X.-L.; Zhu, Z.-Q.; Ren, X.-L. (2010). Model of lean production system for automobile manufacture enterprise, Journal of Mechanical Engineering, Vol. 46, No. 2, 93-98

[10] Wang, Y.-P.; Li, S.-X.; Wang, Z.-Z.; Li, S.-W.; Dong, S.-W.; Cui, L.-X. (2008). Optimization of production logistics process of automobile manufacture enterprise based on Petri net, Journal of Jilin University (Engineering and Technology Edition), Vol. 38, No. S1, 59-62

[11] Qu, L.-P. (2005). Study on current situation and developing strategy of domestic automobile logistics enterprises, Logistics Technology, Vol. 25, No.5, 66-69

[12] Cao, Y.-H.; Peng, H.-G.; Ma, H.-Y. (2009). Application of simulation technology based on Flexsim on production line, Journal of Zhejiang University of Science and Technology, Vol. 21, No. 1, 10-14

[13] Bao, S.-Q.; Chen, H.-X.; Jiang, G.-J.; Zhou, X.-H. (2008). Optimizing the logistics of streamline based on software Flexsim, Industrial Engineering and Management, Vol. 13, No. 4, 106-109

[14] Zhang, X. P.; Peng, Y.; Wu, C. J. (2009). Logistics system modelling and simulating software, $1^{\text {st }}$ edition, Zhejiang University Press, Hangzhou

[15] Li, C.-J.; Xiao, S.-M.; Zhu, X.-C. (2007). Production logistics system modeling and simulation based on Petri net and Flexsim, Machinery Design and Manufacture, Vol. 45, No. 12, 62-64

[16] Tang, X.-Y.; Leng, X.-M.; Yang, L.-L.; Shang, R.; Wang, M.-J. (2011). Application of Flexsim based production line logistics simulation, Logistics Technology, Vol. 30, No. 12, 157-159

[17] Song, J.-X.; Xu, L.; Song, Y.-Z. (2007). Simulation of modern productive logistics system, Logistics Sci-Tech, Vol. 30, No. 3, 93-95

[18] Yan, H. T. (2003). Application of the system simulation technology in logistics system design, Logistics \& Material Handling, Vol. 8, No. 9, 62-65

[19] Ran, M.-H.; Zhang, Y.-G.; Zhang, W.-Y.; Wang, Z.-M. (2013). Simulation research on production logistics system based on Flexsim, Machinery, Vol. 40, No. 6, 57-60

[20] Seebacher, G.; Winkler, H.; Oberegger, B. (2015). In-plant logistics efficiency valuation using discrete event simulation, International Journal of Simulation Modelling, Vol. 14, No. 1, 60-70, doi:10.2507/IJSIMM14(1)6.289

[21] Zhang, W.; Cao, W.-B. (2009). Evaluation on facility layout scheme of production logistics system, Network Fortune, No. 2, 38-40

[22] Wang, K.; Gao, Q.; Wang, D.-S.; Wang, H.-Y. (2007). E-R model based maintenance personnel deploy method, Logistics Sci-Tech, Vol. 30, No. 11, 113-115 